\title{
Future Perspectives for Patient-Centric Pharmaceutical Drug Product Design with Regard to Solid Oral Dosage Forms
}

\author{
Nélio Drumond ${ }^{1}$ (D) \\ Published online: 12 October 2019 \\ (C) The Author(s) 2019
}

\begin{abstract}
Purpose Additional costs for healthcare provision are expected for cases where the level of care provided is not according to the patient's needs and demands. To address these issues and reduce costs, fundamental changes need to be made on how healthcare provision is administered to patients, which raises the opportunity for the implementation of patient-centric systems.

Methods This review addresses the importance of implementing a patient-centric approach in current healthcare provision and emphasizes the need to adjust current development and business models for a successful application of patient-centric care.

Results To increase awareness and avoid confusion, the purpose of patient-centric pharmaceutical drug product design is reviewed in detail and future market opportunities for patient-centric drug products are discussed.

Conclusions With regard to solid oral dosage forms, the subject of patient-centric pharmaceutical drug product design will focus more on the customization of existing technologies (e.g., dosage form size reduction) to address the needs of specific patient populations such as pediatrics, geriatrics, dysphagia patients, or the cognitively impaired.
\end{abstract}

Keywords Patient-centric pharmaceutical development $\cdot$ Healthcare provision $\cdot$ Drug products $\cdot$ Patient needs $\cdot$ Product characteristics $\cdot$ Drug product design

\section{Introduction}

In current days, the majority of healthcare systems across the industrialized countries are facing global challenges. These challenges are related to the constantly increasing costs of basic healthcare provision, with no optimal improvements in the level of care provided to the patients [1,2].

The governmental institutions and involved industries play a crucial role in shaping the way that healthcare is administered to the patients. Yet, their focus is still maintained in keeping healthcare and innovation costs at minimum levels in order to reduce the financial burden, which later is reflected by healthcare solutions that do not always fit the needs of the patients. As a result, additional costs for healthcare provision are expected for cases where the patients are not comfortable with the options offered by healthcare professionals $[3,4]$.

Nélio Drumond

nelio.drumondfreitas@student.tugraz.at

1 Graz University of Technology, Inffeldgasse 13, 8010 Graz, Austria
To address these issues and reduced healthcare costs, fundamental changes need to be made on how healthcare provision is administered to patients, which raises the opportunity for the implementation of patient-centric systems [5]. A patient-centric approach does not require specific rules or guidelines, as it simply involves patients in their healthcare progression and allows them to receive the most appropriate treatment at a reasonable cost. By placing the patients' needs in first place, the patient-centric model will require a high level of both patient and healthcare professional commitment, responsibility, and accountability to deliver efficacious treatments while reducing costs [6]. If successfully applied, this model can benefit every segment of healthcare provision by improving the general health of patients and reducing global expenses for payers and governmental institutions.

The purpose of this review is (i) to address the importance of implementing a patient-centric approach in current healthcare provision, (ii) to emphasize the need of modifying current development and business models for a successful application of patient-centric care, (iii) to clarify the importance of patient-centric pharmaceutical drug product design, and (iv) to discuss future market opportunities in which patient-centric pharmaceutical products can bring added value to patients. 


\section{The Patient-Centric Model in Healthcare Provision}

Patient-centric care is a term that has been increasingly used in recent research reports and clinical settings, however, it is still not very clear what it means. A common assumption is that patient-centric relates to the involvement of the patient in the healthcare process and its interaction with healthcare providers [7]. Although correct, patient centricity is a much broader subject that was designed to account patients' individual preferences, values, and beliefs in the selection of their therapeutic choices by healthcare professionals [8]. It helps patients and their caregivers to communicate and make informed healthcare decisions, allowing them to have an active voice in assessing which healthcare options are more valuable for each specific case $[9,10]$. Notwithstanding, if patientcentric care is simply related to the patient's involvement in the selection of its treatment or care, then words like "engaged" or "empowered" could easily replace centricity [11]. The word centricity is used to demonstrate that the patient is at the center from start to finish during healthcare provision (Fig. 1), and all the involved professionals are invited to help the patient in navigating the decision-making process to make it more personally useful $[12,13]$.

Yet, this process is not simple and requires a deep understanding of the patient's capabilities to codify the information provided from the different healthcare professionals. An adequate interaction between both parts has to be built, where patients can guide the professionals through the different steps of healthcare provision and help them to select the best treatment options which will bring the best outcome for the patients' wellness $[2,14]$.

As patients cannot be instantaneously empowered with knowledge and experience to manage their healthcare alone, the involved professionals need to be adequately informed about patients' health literacy, knowledge, and power disparities, in order to provide them valuable tools that can contribute for an appropriate decision of which therapeutic approach to follow [15]. With this regard, since the final decision relies on the patient, an active participation is highly beneficial and centricity can be supported by constant updates of the healthcare needs of the patient [16]. As the patients will be highly involved in their therapeutic choices and can adequately address their needs, an increase in the efficacy of prescribed treatments will be expected, leading to a decrement on the incidence of potential hospitalizations [17, 18].

\section{Implementation of the Patient-Centric Model Requires Modification of Current Development and Business Patterns}

The costs related to patients' nonadherence to prescribed therapies is estimated to be approximately US $\$ 100$ billion per year [19]. Adherence and effectiveness of treatments were identified to have a great impact on the general health of the population by reducing medical costs related to cases of improper use of drug products, nonadherence, or adverse drug reactions [20]. These numbers might be reflected by a pharmaceutical business model that is stagnated over the years and
Fig. 1 The patient at the center during healthcare provision as a basis for patient-centric model




needs to be restructured in order to fulfill current healthcare demands [21, 22]. This creates an opening for new critical thinking for redefinition of the model, preferably to one in which the patient plays a central role [23]. Moreover, it launches opportunities for the development of new technologies that can increase adherence and patient compliance to medication regimens [24].

New guidelines have addressed the need for drug products to be designed according to the specific needs of the targeted patient population [25]. Nevertheless, based on the current model used for clinical trials, the patients' characteristics are not appropriately addressed. Even though the major user group for a new drug product is known, the targeted patient population is usually not represented in the clinical trials conducted $[26,27]$. In addition, the implementation of patientreported outcomes during clinical trials can highly contribute for the development of optimized designs (e.g., dosage form and packaging) based on the patient's feedback and experience with the drug product [28]. This approach will contribute for increased patient adherence after the launch of the drug product in the market while reducing treatment costs [29]. With this in mind, a Patient-Centered Outcomes Research Institute was implemented in Washington (USA) in 2010, proving that efforts are being made for the development and expansion of a patient-centric healthcare system [30].

\section{Patient-Centric Pharmaceutical Drug Product Design}

Patient-centric pharmaceutical drug product design is a broad term that combines the terms "pharmaceutical drug product design" and "patient centricity." The topic was created to address the need for considering the targeted patient population characteristics in the product design. As such, the drug product should include non-complex elements that intuitively lead the patient to use it easily and as intended, preventing adherence problems or administration errors [7].

The constant improvements in healthcare provision and the continuous discovery of new therapies for several diseases have led to the increase of special patient populations such as very old and multi-morbid, cancer survivors, and dementia patients [31]. Alongside, medication management with regard to these patients becomes very complex due to an increase in the number of drug products, dosage forms, and dosing frequency [32]. The capability of these patients to manage complex medication is very limited and may have to rely on caregivers [33]. This is a predictor for a higher incidence of medication errors and poor adherence for cases where patients do not feel comfortable with their drug regimens [34-36]. Therefore, patient-centric pharmaceutical drug product design plays a crucial role in developing or designing pharmaceutical products according to patients' needs.
A patient-centric design approach can be taken by identifying specific characteristics (skills, impairments, comorbidities) of the targeted patient population that might restrain their usage of drug products and consider them to design appropriate pharmaceutical products. As example, patients with limited manual dexterity (e.g., due to arthritis) may not be able to access the medication contained in a child-resistant packaging [37, 38]. Other cases can include patients that may experience difficulty in reading the product label or understanding the package leaflet due to poor visual acuity and low literacy, respectively [39]. By applying a patient-centric model, increase attention would be given to the packaging design and opening mechanism during development of the pharmaceutical product. Therefore, anticipating the characteristics of the targeted patient population at the time of product design is likely to generate an optimized pharmaceutical product that delivers the specific needs of patients in a real-world setting, something which is not taken into account in current randomized clinical trials [40].

In order to generate a patient-centric basis for guidance during pharmaceutical development, a system composed of design drivers, design inputs, and design outputs can be implemented. The design drivers and design inputs are derived from the targeted patient population and can be identified through routine checkups (e.g., geriatric assessments). Subsequently, patients and healthcare professionals (e.g., doctor, nurse and pharmacist) must work together to identify the most important design outputs and select the most suited pharmaceutical drug product accordingly. This will then contribute for an optimal interaction between the patient and the drug product, which will ultimately lead to an appropriate use and effective treatment $[7,41]$. Since patients present different health literacies, the efficient delivery of relevant product information by healthcare professionals will also play an important role in the treatment success [42-44]. Studies involving patient-reported outcomes will become an integrating tool of patient-centric pharmaceutical drug product design, as they will collect feedback on experience of patients with a specific drug treatment and contribute for a greater understanding of product design $[45,46]$.

\section{Future Perspectives for Patient-Centric Pharmaceutical Design Regarding Solid Oral Dosage Forms}

Over the years, research and development activities in academic, pharmaceutical and research organizations have contributed for new innovative products and scientific know-how. This has led to a constant increase in the number of novel dosage forms and formulation technologies available to the patients. Nevertheless, the majority of drug products available on the market remain as solid oral dosage forms [47]. 
For drugs that can be delivered orally, solid oral dosage forms are and will continue as main drug delivery technology due to its technological applications, which can be applied or adapted to meet patients' needs (e.g., taste masking and extended-release). In addition, the development and manufacturing of solid oral dosage forms are very well established in the pharmaceutical industry and it is the technology of choice whenever applicable due to its cheaper price.

With regard to solid oral dosage forms, the subject of patient-centric pharmaceutical drug product design will focus more on the customization of existing technologies (e.g., dosage form size reduction) to address the needs of specific patient populations such as pediatrics, geriatrics, dysphagia patients, or mentally ill patients [48]. One frequent issue that affects all these patient populations when practicing drug therapy is their inability to swallow tablets or capsules. In pediatric patients, there is often a fear of chocking during the administration of the dosage form, whereas mentally ill patients often skip their medications by hiding the dosage form in their cheeks [49]. Considering geriatric and dysphagic patients, there is a general difficulty to swallow related to a deterioration of the swallowing function due to aging, specific diseases, or co-morbidities, which challenges the oral administration of drug products [50]. These situations raise opportunities for patient-centric research, as these issues can be addressed with the development of patient-centric pharmaceutical drug products that can complement the specific needs of each specific patient, increasing therapeutic efficacy and patient compliance [47].

In the past, compliance to prescribed treatments could be adopted through simple variations on the physical appearance of drug products, mainly related to changes in size, shape, or color. In addition, extended-release formulations or combined products have also helped to decrease the dosing frequency and pill burden. Recent developments in patient-friendly dosage forms were achieved with the development of orally disintegrating tablets [51]. It is usually stated that these are easy-to-swallow dosage forms, which allow the administration of a tablet that can be swallowed in the form of a liquid or suspension. Nevertheless, the administration of a liquid formulation can be associated with a higher risk for aspiration when compared to solid forms with regard to dysphagic patients [52].

Other progress in patient-centric dosage forms were performed to address drug delivery among pediatric populations. Liquid formulations such as syrups and suspensions have for long been considered the most appropriate type of dosage form for young children. Nevertheless, liquid formulations present several problems during administration such as bad taste and dose-measuring errors [53, 54]. The introduction of new European Medicine Agency (EMA) guidelines addressing the development of appropriate medicines for the pediatric population $[55,56]$ led to a general understanding that solid oral dosage forms such as multiparticulate and minitablets are suitable patient-centric options, enabling proper administration, flexible dosing, and high acceptability in young children [57-59]. In addition to pediatrics, the same approach should be applied to specific patient populations suffering from diseases that affect the activity of voluntary muscles such as amyotrophic lateral sclerosis (ALS) and muscular dystrophy, which will ultimately lead to patients with impaired swallowing function and impact oral administration of drug products.

Considering older adults, a similar approach was recently applied by EMA to encourage the pharmaceutical development of appropriate medicines that can address the specific needs of this special patient population [60]. Although regulatory proceeding has started, real technology progresses are yet to be made [61]. Since older patients tend to present an aged and deteriorated swallowing function (dysphagia), these may also struggle to swallow large tablets and capsules. Therefore, the patient-centric approach currently in development for the pediatric population can also be transferred to the geriatric population, as these patients would benefit from solid oral dosage forms such as minitablets or multiparticulate systems to facilitate oral drug administration and increase efficacy and safety of prescribed treatments by reducing the cases of drug product manipulation to improve swallowability.

During the development of solid oral dosage form drug products, a wide range of presentations should be manufactured to meet specific needs of different patient populations. In addition to the typical manufacturing of conventional tablets and capsules that typically meet the needs of the normal adult population, the manufacturing of dosage form size-reduction presentations should also be considered and introduced during routine development. This approach will lead to drug products that can globally impact patients and enhance therapy regimens, as it would not only meet the standard needs of the adult population but also the needs for pediatrics, older adults, and patients suffering from swallowing issues due to specific conditions [62]. For cases of drug products which remain in a conventional tablet or capsule presentation (e.g., high drug loads), a patient-centric approach could involve the development of appropriate surface conditions that can aid the swallowability and gliding properties of tablets and capsules during oro-esophageal transit. This can be obtained through the development of new coating technologies that present poor mucoadhesive properties and increased gliding performance across the oro-esophageal system [63]. Since the currently available options still do not meet patients' needs for enhanced swallowability, it is therefore expected an increase in methodological research for the development of appropriate surface coatings that can optimize the swallowing function and administration safety of solid dosage forms [64-66].

Patient centricity is expected to have a huge impact in the quality of life of future generations. Consequently, the involved stakeholders need to adapt and integrate a patient- 
centric approach into their visions, which will allow them to remain competitive and deliver innovative solutions for current patient needs. Substantial efforts have already been made through the development of patient-centric departments or creation programs to keep a closer relationship with patients. Notwithstanding, the pharmaceutical industry and related organizations are still far from reaching its full potential, and a higher predominance of patient centricity in healthcare provision will be expected in future years.

\section{Conclusion}

In the years to come, a higher predominance of patient-centric research and patient-centric healthcare systems is expected to be established across developed countries. The adoption of a patient-centric care is expected to benefit patients and contribute for huge savings with healthcare costs. Through a solid commitment of all parts involved, patients will be highly engaged to their therapeutic choices, as these will appropriately address their specific needs. This will contribute for higher adherence levels and reduced events of medication errors or potential adverse drug reactions, which eventually reflect less number of hospitalizations. The recent updates in regulatory regulations encouraging the developing appropriate medicines for special patient populations (e.g., pediatrics and geriatrics) indicate that patient-centric pharmaceutical drug product design is slowly getting shape, with the involved industries also starting to adapt to this new reality. As such, a higher attention and dedication to dosage size reduction during development and manufacturing of solid oral dosage forms will become a standard routine and drug product presentations in the form of multiparticulate systems or minitablets are expected to be more frequent in the upcoming years.

Funding Information Open access funding provided by Graz University of Technology.

\section{Compliance with Ethical Standards}

Research Involving Human Participants and/or Animals This article does not contain any studies with human participants or animals performed by the author.

Informed Consent Informed consent is not applicable to this article

Disclaimer The views expressed in this publication are those of the author only and should not be considered as the view of Graz University of Technology nor any of their working parties or committees.

Open AccessThis article is distributed under the terms of the Creative Commons Attribution 4.0 International License (http:// creativecommons.org/licenses/by/4.0/), which permits unrestricted use, distribution, and reproduction in any medium, provided you give appropriate credit to the original author(s) and the source, provide a link to the Creative Commons license, and indicate if changes were made.

\section{References}

1. IBM Corporation. Patient-Centric: the 21st Century Prescription for Healthcare. 2006. https://www-03.ibm.com/industries/ca/en/ healthcare/files/060516_PatientCentric_Briefing.pdf. Accessed 05 Oct 2017.

2. Levit L, Balogh E, Nass S, Al E. Patient-centered communication and shared decision making, in delivering high-quality cancer care: charting a new course for a system in crisis. Washington DC: The National Academies Press; 2013. p. 91-152.

3. Tang N, Eisenberg JM, Meyer GS. The roles of government in improving health care quality and safety. Jt Comm J Qual Saf. 2004:30:47-55. https://doi.org/10.1016/S1549-3741(04)30006-7.

4. Iuga AO, McGuire MJ. Adherence and health care costs. Risk Manag Healthc Policy. 2014;7:35-44. https://doi.org/10.2147/ RMHP.S19801.

5. Chen J, Mullins CD, Novak P, Thomas SB. Personalized strategies to activate and empower patients in health care and reduce health disparities. Health Educ Behav. 2016;43:25-34. https://doi.org/10. 1177/1090198115579415.

6. Greene SM, Tuzzio L, Cherkin D. A framework for making patientcentered care front and center. Perm J. 2012;16:49-53 http://www. pubmedcentral.nih.gov/articlerender.fcgi?artid=3442762\&tool= pmcentrez\&rendertype=abstract. Accessed 17 Oct 2017.

7. Stegemann S, Ternik RL, Onder G, Khan MA, Van Riet-Nales DA. Defining patient centric pharmaceutical drug product design. AAPS J. 2016. https://doi.org/10.1208/s12248-016-9938-6.

8. Yeoman G, Furlong P, Seres M, Binder H, Chung H, Garzya V, et al. Defining patient centricity with patients for patients and caregivers: a collaborative endeavour. BMJ Innov. 2017;3:76-83. https://doi.org/10.1136/bmjinnov-2016-000157.

9. Williams SL, Haskard KB, DiMatteo MR. The therapeutic effects of the physician-older patient relationship: effective communication with vulnerable older patients. Clin Interv Aging. 2007;2:453-67.

10. PCORI. Patient-centered outcomes research, http://www.pcori.org/ what-we-do/pcor. Accessed 11 Oct 2017.

11. Robbins DA, Curro FA, Fox CH. Defining patient-centricity: opportunities, challenges, and implications for clinica care and research. Ther Innov Regul Sci. 2013;47:349-55. https://doi.org/10. 1177/2168479013484159.

12. Curro F, Thompson VP, Naftolin F, Grill A, Vena D, Terracio L, et al. Practice-based research network infrastructure design for institutional review board risk Assessment and generalizability of clinical results. Ther Innov Regul Sci. 2013;47:82-9.

13. Curro FA, Robbins DA, Naftolin F, Grill AC, Vena D, Terracio L. Person-centric clinical trials: defining the N-of- 1 clinical trial utilizing a practice-based translational network. Clin Investig. 2015;5: 145-59. https://doi.org/10.1016/S2215-0366(16)30284-X. Epidemiology.

14. Huang F, Driga A, LeGuerrier BE, Schmitz R, Hall-Lavoie DM, Kostaras X, et al. Supporting patients with incurable cancer: backup behavior in multidisciplinary cross-functional teams. J Oncol Pract. 2016;12:1123-34. https://doi.org/10.1200/JOP.2016.013912.

15. Fisher E. Building a medical neighborhood for the medical home. $\mathrm{N}$ Eng1 J Med. 2008;359:1202-5. https://doi.org/10.1056/ NEJMp0806233.

16. Vahdat S, Hamzehgardeshi L, Hessam S, Hamzehgardeshi Z. Patient involvement in health care decision making: a review. Iran Red Crescent Med J. 2014;16:1-7. https://doi.org/10.5812/ircmj. 12454.

17. S. Collins, K.B.K. Piper, G. Owens, The opportunity for health plans to improve quality and reduce costs by embracing primary care medical homes., Am Health Drug Benefits 6 (2013) 30-38. /pmc/articles/PMC4031704/?report=abstract. 
18. Bertakis KD, Azari R. Patient-centered care is associated with decreased health care utilization. J Am Board Fam Med. 2011;24: 229-39. https://doi.org/10.3122/jabfm.2011.03.100170.

19. Hughes CM. Medication non-adherence in the elderly: how big is the problem? Drugs Aging. 2004;21:793-811

20. Haynes R, McDonald H, Garg A, Montague P. Interventions for helping patients to follow prescriptions for medications, Cochrane Database Syst Rev. 2002;CD000011. https://doi.org/10.1002/ 14651858.CD000011.

21. Taylor D. The pharmaceutical industry and the future of drug development. Pharm Environ. 2015;1-33. https://doi.org/10.1039/ 9781782622345-00001.

22. Stegemann S, Bresciani M. Design of pharmaceutical products to meet future patient needs requires modification of current development paradigms and business models. Z Gerontol Geriatr. 2014;47: 336. https://doi.org/10.1007/s00391-014-0658-1.

23. Rao SK. Rethinking commercial strategy - a patient-centered commercial model. J Commer Biotechnol. 2010;16:206-23. https://doi. org/10.1057/jcb.2010.10.

24. Sabaté E. Adherence to long-term therapy: evidence for action. Geneva: World Health Organization, WHO; 2003. http://www. who.int/chronic_conditions/en/adherence_report.pdf. Accessed 17 Oct 2017.

25. EMA. ICH guideline Q8 (R2) on pharmaceutical development. 2015;1-24. EMEA/CHMP/167068/2004-ICH.

26. Cerreta F, Eichler H-G, Rasi G. Regulating compounding pharmacies after NECC. N Engl J Med. 2012;367:1969-72. https://doi.org/ 10.1056/NEJMp1212667.

27. Sharma NS. Patient centric approach for clinical trials: current trend and new opportunities. Perspect Clin Res. 2015;6:134-8. https:// doi.org/10.4103/2229-3485.159936.

28. Kwan BM, Sills MR, Graham D, Hamer MK, Fairclough DL, Hammermeister KE, et al. Stakeholder engagement in a patientreported outcomes (PRO) measure implementation: a report from the SAFTINet practice-based research network (PBRN). J Am Board Fam Med. 2016;29:102-15. https://doi.org/10.3122/jabfm. 2016.01.150141.

29. Bosworth HB, Granger BB, Mendys P, Pharm D, Burkholder R, Czajkowski SM, et al. Medication adherence: a call for action. Am Heart J. 2011;162:412-24. https://doi.org/10.1016/j.ahj.2011.06. 007.Medication.

30. Selby JV, Beal AC, Frank L. The Patient-Centered Outcomes Research Institute (PCORI) national priorities for research and initial research agenda. JAMA. 2012;307:1583-4. https://doi.org/10. 1001/jama.2012.500.

31. Nobili A, Marengoni A, Tettamanti M, Salerno F, Pasina L, Franchi $\mathrm{C}$, et al. Association between clusters of diseases and polypharmacy in hospitalized elderly patients: results from the REPOSI study. Eur J Intern Med. 2011;22:597-602. https://doi.org/10.1016/j.ejim. 2011.08.029.

32. Libby AM, Fish DN, Hosokawa PW, Linnebur SA, Metz KR, Nair $\mathrm{KV}$, et al. Patient-level medication regimen complexity across populations with chronic disease. Clin Ther. 2013;35. https://doi.org/ 10.1016/j.clinthera.2013.02.019.

33. Look KA, Stone JA. Medication management activities performed by informal caregivers of older adults. Res Soc Adm Pharm. 2017. https://doi.org/10.1016/j.sapharm.2017.05.005.

34. Boyd CM, Wolff JL, Giovannetti E, Reider L, Weiss C, Xue Q, et al. Healthcare task difficulty among older adults with multimorbidity. Med Care. 2014;52:S118-25. https://doi.org/10. 1097/MLR.0b013e3182a977da.

35. Stenholm S, Westerlund H, Head J, Hyde M, Kawachi I, Pentti J, et al. Comorbidity and functional trajectories from midlife to old age: the health and retirement study. J Gerontol Ser A Biol Sci Med Sci. 2015;70:332-8. https://doi.org/10.1093/gerona/glu113.
36. Ehlenbach WJ, Larson EB, Curtis JR, Hough CL. Physical function and disability after acute care and critical illness hospitalizations in a prospective cohort of older adults. J Am Geriatr Soc. 2015;63: 2061-9. https://doi.org/10.1111/jgs.13663.

37. Atkin P, Finnegan TP, Ogle SJ, Shenfield GM. Functional ability of patients to manage medication packaging: a survey of geriatric inpatients. Age Ageing. 1994;23:113-6. https://doi.org/10.1093/ ageing/23.2.113.

38. Carmeli E, Patish H, Coleman R. The aging hand. J Gerontol. 2003;58A:146-52. https://doi.org/10.1093/gerona/58.2.M146.

39. van Beusekom M, Grootens-Wiegers P, Bos MJW, Guchelaar HJ, van den Broek JM. Low literacy and written drug information: information-seeking, leaflet evaluation and preferences, and roles for images. Int J Clin Pharm. 2016;38(6):1372-9. https://doi.org/ 10.1007/s11096-016-0376-4.

40. Saad ED, Paoletti X, Burzykowski T, Buyse M. Precision medicine needs randomized clinical trials. Nat Rev Clin Oncol. 2017;14:31723. https://doi.org/10.1038/nrclinonc.2017.8.

41. Onder G, Van der cammen TJM, Petrovic M, Somers A, Rajkumar C. Strategies to reduce the risk of iatrogenic illness in complex older adults. Age Ageing. 2013;42:284-91. https://doi.org/10.1093/ ageing/aft038.

42. Greenhalgh T. Health literacy: towards system level solutions. BMJ. 2015;350:h1026. https://doi.org/10.1136/bmj.h1026.

43. Wong PKK, Christie L, Johnston J, Bowling A, Freeman D, Joshua $\mathrm{F}$, et al. How well do patients understand written instructions? Medicine (Baltimore). 2014;93:e129. https://doi.org/10.1097/MD. 0000000000000129.

44. Mullen E. Health literacy challenges in the aging population. Nurs Forum. 2013;48:248-55. https://doi.org/10.1111/nuf.12038.

45. Rothman M, Burke L, Erickson P, Leidy NK, Patrick DL, Petrie CD. Use of existing patient-reported outcome (PRO) instruments and their modification: the ISPOR good research practices for evaluating and documenting content validity for the use of existing instruments and their modification PRO task force report. Value Health. 2009;12:1075-83. https://doi.org/10.1111/j.1524-4733. 2009.00603.x.

46. Liu F, Ranmal S, Batchelor HK, Orlu-Gul M, Ernest TB, Thomas IW, et al. Patient-centred pharmaceutical design to improve acceptability of medicines: similarities and differences in paediatric and geriatric populations. Drugs. 2014;74:1871-89.

47. Reeve BB, Wyrwich KW, Wu AW, Velikova G, Terwee CB, Snyder $\mathrm{CF}$, et al. ISOQOL recommends minimum standards for patientreported outcome measures used in patient-centered outcomes and comparative effectiveness research. Qual Life Res. 2013;22:1889 905. https://doi.org/10.1007/s11136-012-0344-y.

48. Maalouf N. Developing patient-centric drug formulations to meet patient needs, Business Dev Licens J. 2013.

49. Latha K. The noncompliant patient in psychiatry: the case for and against covert/surreptitious medication. Mens Sana Monogr. 2010;8:96-121.

50. Stegemann S, Gosch M, Breitkreutz J. Swallowing dysfunction and dysphagia is an unrecognized challenge for oral drug therapy. Int $\mathrm{J}$ Pharm. 2012;430:197-206.

51. Hannan PA, Khan JA, Khan A, Safiullah S. Oral dispersible system: a new approach in drug delivery system. Indian J Pharm Sci. 2016;78:2-7.

52. Schiele JT, Penner H, Schneider H, Quinzler R, Reich G, Wezler N, et al. Swallowing tablets and capsules increases the risk of penetration and aspiration in patients with stroke-induced dysphagia. Dysphagia. 2015;30:571-82. https://doi.org/10.1007/s00455-0159639-9.

53. van Riet-Nales DA, de Jager KE, Schobben AF a M, Egberts TCG, a Rademaker CM. The availability and age-appropriateness of medicines authorized for children in the Netherlands. Br J Clin 
Pharmacol. 2011;72:465-73. https://doi.org/10.1111/j.1365-2125. 2011.03982.x.

54. Drumond N, van Riet-Nales DA, Karapinar-Çarkit F, Stegemann S. Patients' appropriateness, acceptability, usability and preferences for pharmaceutical preparations: results from a literature review on clinical evidence. Int J Pharm. 2017;521:294-305. https://doi. org/10.1016/j.ijpharm.2017.02.029.

55. The European Parliament and The Council of the European Union. Regulation of the European Parliament and of the Council on medicinal products for paediatric use and amending Regulation. Off J Eur Union. 2006;378:/1-378/19.

56. EMA, Reflection paper: Formulation of Choice for the Paediatric Population (EMEA/CHMP/PEG/194810/2005), Guideline. 2006. EMEA/CHMP/PEG/194810/2005.

57. Klingmann V, Spomer N, Lerch C, Stoltenberg I, Frömke C, Bosse $\mathrm{HM}$, et al. Favorable acceptance of mini-tablets compared with syrup: a randomized controlled trial in infants and preschool children. J Pediatr. 2013;163:1728-33. https://doi.org/10.1016/j.jpeds. 2013.07.014.

58. Klingmann V, Seitz A, Meissner T, Breitkreutz J, Moeltner A, Bosse HMA. Acceptability of uncoated mini-tablets in neonates-a randomized controlled trial. J Pediatr. 2015;167:893-6. https://doi. org/10.1016/j.jpeds.2015.07.010.

59. Spomer N, Klingmann V, Stoltenberg I, Lerch C, Meissner T, Breitkreutz J. Acceptance of uncoated mini-tablets in young children: results from a prospective exploratory cross-over study. Arch Dis Child. 2012;97:283-6. https://doi.org/10.1136/archdischild2011-300958.

60. European Medicines Agency. Reflection paper on the pharmaceutical development of medicines for use in the older population, 44. 2017. http://www.ema.europa.eu/docs/en GB/document_library/
Scientific_guideline/2017/08/WC500232782.pdf. Accessed 25 Oct 2017.

61. van Riet-Nales DA, Hussain N, Sundberg KAE, Eggenschwyler D, Ferris C, Robert JL, et al. Regulatory incentives to ensure better medicines for older people: from ICH E7 to the EMA reflection paper on quality aspects. Int J Pharm. 2016;512:343-51. https://doi. org/10.1016/j.jppharm.2016.05.001.

62. Marconati M, Raut S, Burbidge A, Engmann J, Ramaioli M. An in vitro experiment to simulate how easy tablets are to swallow. International Journal of Pharmaceutics. 2018;535 (1-2):27-37

63. Drumond N, Stegemann S. An evaluation of the gliding performance of solid oral dosage form film coatings using an artificial mucous layer. Colloids and Surfaces B: Biointerfaces. 2019;177: 235-241

64. Drumond N, Stegemann S. Polymer adhesion predictions for oral dosage forms to enhance drug administration safety. Part 1: in vitro approach using particle interaction methods. Colloids Surf B Biointerfaces. 2018;165:9-17.

65. Drumond N, Stegemann S. Polymer adhesion predictions for oral dosage forms to enhance drug administration safety. Part 2: in vitro approach using mechanical force methods. Colloids Surf B Biointerfaces. 2018;166:17-23.

66. Drumond N, Stegemann S. Polymer adhesion predictions for oral dosage forms to enhance drug administration safety. Part 3: review of in vitro and in vivo methods used to predict esophageal adhesion and transit time. Colloids Surf B Biointerfaces. 2018;165:303c14.

Publisher's Note Springer Nature remains neutral with regard to jurisdictional claims in published maps and institutional affiliations. 